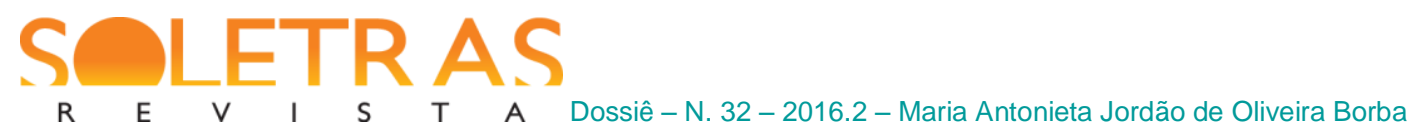

\title{
Contribuições da teoria do efeito e do discurso filosófico para contemplar as artes visuais
}

\author{
Maria Antonieta Jordão de Oliveira Borba ${ }^{1}$ \\ Universidade do Estado do Rio de Janeiro
}

Resumo: Leitura do quadro Las meninas, de Diego Velásquez, a partir de concepções diferenciadas da Teoria da literatura, em especial da Teoria do efeito estético de Wolfgang Iser. Percepções fenomenológicas e configurações conceituais, provenientes da produção e da recepção do discurso, sejam sintaxes linguísticas, sejam semiológicas. O encontro entre o artista e o leitor/espectador. Impressões sobre O Corvo, de Edgar Allan Poe, na ilustração do efeito resultante do prazer estético. Por estas diretrizes, o artigo se desenvolve no sentido de permitir que a escrita revele os dados de lembranças perceptivas por se deixar levar pelas ocorrências perceptivas, como se estivessem ocorrendo no momento mesmo de sua produção receptiva. Nesse processo de interação de leitor/espectador com obra/artista como experimentação da fenomenologia do Ato de leitura de Iser, imagens, conceitos, discursos filosóficos, contos, ensaios, tudo vem habitar essa dobra, conforme Gilles Deleuze, pela qual o próprio artigo se quer construir. Trata-se, enfim, de um modo diferenciado de desenvolvimento de escrita ensaística sobre objeto, voltado para o objetivo de contribuir para uma reflexão do campo expandido da arte, em que não se caracteriza propriamente pela interdisciplinaridade, mas por ideias e linhas de pensamento que, transdisciplinares, tocam-se eventualmente em uma nova crítica da arte.

Palavras-chave: Fenomenologia. Percepção. Efeito. Recepção. Teoria da arte.

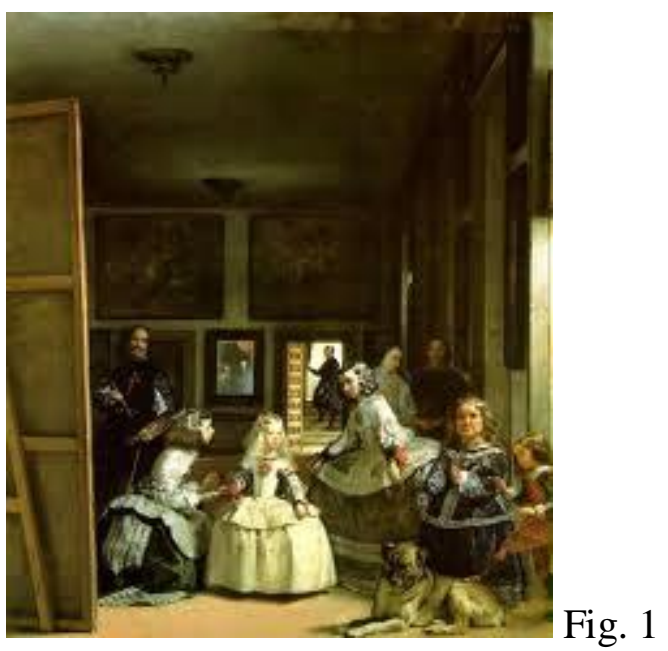

\footnotetext{
${ }^{1}$ Doutora em Ciência da literatura pela Universidade Federal do Rio de Janeiro (1994), pós-doutora em Filosofia pelo Departamento de filosofia da Pontifícia Universidade Católica do Rio de Janeiro, sob a supervisão do Professor Paulo Cesar Duque-Estrada, mestre em Letras, também pela Pontifícia Universidade Católica do Rio de Janeiro (1984). Atualmente é Pesquisadora visitante do Instituto de Letras da UERJ, na categoria Associado, atuando em regime de dedicação exclusiva nos cursos de pós-graduação em Letras. (informações retiradas do Currículo Lattes)
}

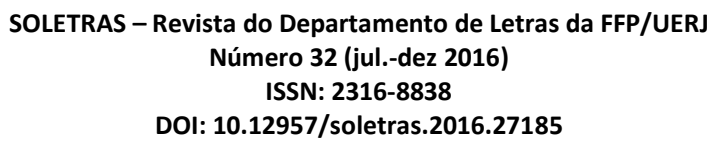


Em sua obra intitulada Las meninas, Diego Velásquez ${ }^{2}$ (Fig.1) compôs o gesto de afastamento de um pintor que trabalha num quadro, sinalizando para um momento de contemplação de seu objeto e, simultaneamente, fazendo um convite para que o espectador com ele compartilhe a poiesis, a aisthesis, a katharsis ${ }^{3}$ (JAUSS, 1979, p.65). Num gesto que parece recuo de passo pelo qual o pintor, no interior da tela, se mostra ao público, ele se revela arte para que, a partir da recepção, o quadro integral de Velásquez dê início ao trânsito com a produção. A imagem é capaz de suscitar uma espécie de gestalt, em que os variados elementos do processo perceptivamente se revezam e se tornam cúmplices na arte. Concebida nessa fenomenologia, o espectador dirá que será em tal plasticidade participativa que o prazer estético quer se instalar. A intervenção ocorre na emergência de um momento como se da arte estivesse conceitualmente orientada de liberação de e liberação para, ambas realizadas pela poiesis - produção de obra no mundo - até a possibilidade de renovação da percepção interna e externa na consciência receptora - aisthesis - sempre que as sensações provocadas pelo discurso forem capazes de liberar o espírito e abalar convicções de espectadores, leitores, ouvintes, e, então, conduzi-los à katharsis.

Direcionando o olhar de volta, agora para as cenas vizinhas à figura do pintor, reconhecemos, no todo, o fenômeno que as mantêm assim tão caras à tradição e, ao mesmo, tempo capazes de desautomatizar o cotidiano, desfamiliarizando percepções estéticas até a contemporaneidade, em sucessivos horizontes de expectativa, desde o século XVII. Nessa época, eram concepções epistemológicas de mundo que pautavam a emergência de uma concepção de sujeito dono de si, condutor de sua história, capaz tanto de representar quanto de se representar. Sobre esse percurso na história, é possível que a obra de Velásquez tenha antecipado o diferente na sólida produção artística do Ocidente, se a compreensão do

\footnotetext{
${ }^{2}$ Diego Velásquez. As meninas; 318x276cm; óleo sobre tela; Museu do Prado, Madri.

${ }^{3}$ Hans Robert Jauss, "O Prazer estético e as experiências fundamentais da poiesis, aisthesis e katharsis". In: COSTA LIMA, Luiz. (org.) A lliteratura e o lleitor: textos de estética da recepção, RJ: Paz e Terra, 1979, p.4382. Jauss sintetiza assim essas conceituações: Resumo esta exposição na tese seguinte citação: "a conduta do prazer estético, que é ao mesmo tempo liberação de e liberação para realiza-se por meio de três funções: para a consciência produtora, pela criação do mundo como sua própria obra (poiesis); para a consciência receptora, pela possibilidade de renovar sua percepção, tanto na realidade externa, quanto na interna (aisthesis); e, por fim, para que a experiência subjetiva se transforme em intersubjetiva, pela anuência ao juízo exigido pela obra, ou pela identificação com normas de ação predeterminadas a serem explicitadas." (p.81). Escreve Jauss, ainda, o seguinte: "Designa-se por katharsis (...) aquele prazer dos afetos provocados pelo discurso ou pela poesia, capaz de conduzir o ouvinte e o espectador tanto à transformação de suas convicções, quanto à liberação de sua psique" (p.81).
} 
fenômeno é vista como ocorrência do que T. S. Elliot, em 1919, conceituou como o novo em poesia.

\begin{abstract}
"Nenhum poeta, nenhum artista, tem sua significação completa sozinho. Seu significado e a apreciação que dele fazemos constituem a apreciação de sua relação com os poetas e os artistas mortos. Não se pode estimá-lo em si; é preciso situá-lo para, contraste e comparação, entre os mortos. Entendo isso como um princípio de estética, não apenas histórico, mas no sentido crítico. É necessário que ele seja harmônico, coeso, e não unilateral; o que ocorre quando uma nova obra de arte aparece é, às vezes, o que ocorre simultaneamente com todas as obras de arte que a precedem. Os monumentos existentes formam uma ordem ideal entre si e esta só se modifica pelo aparecimento de uma nova (realmente nova) obra entre eles." (ELLIOT: 1989, p.43).
\end{abstract}

Longe de nós, lá no Museu do Prado, a tela Las meninas ocupa a "Província da Beleza”, metáfora de Edgar Allan Poe em seu belo ensaio “A Filosofia da composição" (POE, 1999, de que me aproprio pela singularidade com que nomeia a instância da poesia. Retomo-a também pelo desejo de prestar brevíssima homenagem a esse escritor, poeta, artista que nos deixou o legado de uma das mais belas composições da literatura ocidental. Refiro-me agora a O Corvo (POE, 1998), o poema que, por efeito semelhante ao de uma pintura marcada pela excepcionalidade, como a de Velásquez, retira-nos do entorno e nos obriga à pausa na leitura dos versos, ainda que sejam só silenciosamente recitados.

Falar de Velásquez ou lembrar $O$ Corvo constitui, em meio à apreciação da arte, um modo eficaz de os sentidos se deixarem arrebatar pela experiência estética, mobilizados que se veem pelo quadro e pelo poema. Sabemos todos que prescindimos da obra visível em sua materialidade, para vivenciarmos o momento adicional em que o prazer de ordem perceptiva faz com que tomemos uma posição diante do objeto. Mas como esse modo de prazer - o prazer estético ${ }^{4}$ - quer sempre a fruição coparticipante, a melhor maneira de nos deixarmos entregues é retomar o quadro, na contemplação interessada, própria do campo de que trato, tentando reinstaurar sua presença na mente, o que implica fazer do quadro um objeto de puro prazer. Como escreve Lwduig Giez (1971), aprofundando a fenomenologia do prazer estético de Moritz Geiger, “o prazer aponta para o objeto do prazer, que é fruído no isolamento; o prazer estético, de certa forma, elimina este isolamento do prazer, porque agora se toma

\footnotetext{
${ }^{4}$ Escreve Jauss, citando Ludwig Giesz, a importância de se diferenciar o "prazer estético" do "prazer elementar".
} 
posição, se encontra prazer no objeto de prazer" (GIESZ, 1971 p.30). Trata-se, portanto, de uma atitude estética o que me conduz de volta àquele canto esquerdo da tela de Velásquez.

O olhar recusa a fixação inicial em qualquer outra parte da superfície da tela, ainda que ela se desnude por inteira ao espectador que se aproxima. Foi essa a sensação que tive quando entrei no espaço do Museu do Prado onde estava exposto o quadro Las meninas, movida por desejo de logo chegar ali, enquanto percorria a vizinhança cheia de corredores e salões que compõem o prédio da Espanha. Estando ainda um pouco longe da poesia que se abria à visitação, o impulso de usufruir tudo de uma só vez cedeu pacientemente ao gesto de querer o lento acompanhamento sintagmático dos signos visuais dispostos na tela de Velásquez.

Os primeiros versos chegavam da figura do artista até os visitantes em intensa atratividade. Ela, a grande cena, suspende a realidade de mundo para que o observador passe pela vivência do espanto, um efeito que parece ter se desprendido do sensório, sem ainda ter atingido o cognitivo ${ }^{5}$. A sensação é semelhante àquela provocada pelas asas em movimento do Corvo, a ave de mau agouro, que, na escuridão da noite, bate na porta do quarto do amante de Lenora, anunciando o inevitável da dolorosa separação da morte. O nevermore, de significado já tão definidor, insiste em aparecer num refrão, como se precisasse repetir para falar do trágico. Indo adiante nas estrofes, o leitor descobre que era mesmo preciso dizer outra vez, como estética intrínseca à estética do poema. Em cada um dos pronunciamentos, ainda que de natureza inintensificável, o nevermore intensifica a morte na mestria de Poe, à medida que mais e mais amplia a dor. Em O Corvo, nevermore é recurso particularmente elaborado para que o efeito retorne ao observador como resposta trágica. Conclui, então, que, a cada final de estrofe, a significação conduz o amante a uma forma de autotortura. Nesse momento de dor, o estar aí da obra faz com que o leitor aprofunde a sofrida anunciação da morte, sem querer dela se livrar, numa insana tentativa de desafiar o poder junto ao amante. 'Esse deve ser o efeito e a resposta que Poe parece querer de seus leitores' - é possível que assim pense o observador enquanto lê o quadro. Dessa hipótese, chega à confirmação. Era essa mesma a intenção de Poe, embora só tenha sido revelada anos mais tarde, quando publicou a metalinguagem do poema em forma de ensaio sob o título "A filosofia da composição" (POE: 1999) ${ }^{6}$. Também nessa fenomenologia do texto, lemos que cada momento do poema é

\footnotetext{
5 Para W. Iser (ISER:1978), o efeito estético, ultrapassa o sensório, embora ainda não pertença à ordem cognitiva.

${ }^{6}$ O ensaio de Edgar Allan Poe, publicado em 1999, mostra a metodologia por ele utilizada na criação de seu poema O Corvo, do ano de 1845.
} 
cuidadosamente elaborado para que o leitor permaneça na autorreferencialidade da obra, de modo que as coisas de mundo libertem a recepção de quaisquer referências alheias à interação.

E no quadro? Qual o sentido a ser construído a partir da cena em que o pintor se mostra à esquerda? Se a ideia fosse seguir a totalidade da grade de Iser, haveria uma resposta a ser produzida, já quando o espectador se depara com a grande cena, por se tratar da vivência de efeito, momento perceptivo, portanto, que conduziria a um outro imediato, quando a sintaxe do cérebro organiza a percepção. Para Iser (1978), é inevitável a saída do efeito. Não é próprio ao estado perceptivo que o homem nele se estenda ou permaneça, por tender para a cognição. Mas a ideia de seguir a Teoria do efeito não implica, aqui, construir um sentido, resposta ou significação para Las meninas. Antes, pretende-se deixar que as percepções aconteçam, fluam, libertas de qualquer conceituação que interrompa os efeitos ou, ainda, de qualquer outro método que se revista de finalidade teleológica. Volta-se para a tentativa de participar, apenas pela perspectiva de leitora que observa, de uma atitude bem próxima da Teoria (no caso, pensando em arte) que vem sendo elaborada por Roberto Corrêa dos Santos, a partir do que compreende por expansão. Falo de um valioso conjunto de ideias que esse artista e semiólogo vem desenvolvendo em espaços artísticos e acadêmicos diversos por meio de atos e peformances expressos em livros, textos, poemas, intervenções orais e corpóreas. Abaixo, reproduzo fragmento inédito de seu modo de conceber.

"A variedade de questões, surgida no seio de uma Teoria da Arte, em seus não muito afastados sinais de começos, encontra-se agora avolumada por exigências e operações histórico-culturais a serem postas em avaliação, em virtude do alto teor crítico dos atuais atos de arte: atos capazes de recolher, redefinir e expor a massa de problemas de que nascem e a que dão vida, conseguindo assim gerar uma excepcional energia para produzir outras muitas e fortes formas de pensamento - em muitas delas, forte massa de pensamento teórico. Atos em que se cruzam modos de produção e de recepção, abertos a processos formadores de plurais sentidos inscritos em lugares e corpos constantes da vida da cultura. Nesses distintos lugares e corpos, trabalhos de arte são grafados, propondo possibilidades de visão e de entendimento, por meio da formação de circuitos novos e de complexas cadeias de relações; relações observáveis, quando sob o crivo de uma atitude teórica que se situe para além do trabalho disciplinar. Impõe-se, assim, que sejam lidos tais atos de arte como textos, como escrituras, como obras de potência escriptural e plástica. Muitos cruzamentos estabelecem-se de maneira a que se produzam operações artísticas que, valendo-se de outros traços e materiais, não cessam de migrar, constituindo um campo expandido, conforme hoje se configuram seus novos modos de inscrever-se nos espaços: papel, tela, vídeo, massa, rede, proposição mental de ideias - pensamento e plasticidade, pois. Interescriturações construtoras de significâncias que problematizam saberes instituídos, hábitos de entendimento, formas de operar, técnicas de percepção, recusando e rediscutindo os modelos 
consagrados de controle analítico, formulados por aquelas disciplinas que, em seus inícios de formação, estiveram, por algum tempo, confiantes em seus recursos instrumentais." (SANTOS, 2016).

De volta às percepções despertadas por Velásquez, encontramos o pincel longo, suspenso pelo braço do pintor, e o corpo recuado num passo para trás. Imaginamos o gesto sugerindo um instante em que o artista assim se posicionou para que melhor pudesse avaliar o efeito de nobreza, indispensável para que a pintura, em sua época, ocupasse, de vez, o Panteão das grandes artes. A pesquisa historiográfica já informou o esforço empreendido por Velásquez para firmar a pintura como arte liberal e dela retirar-lhe qualquer suspeita de status artesanal, um estigma ainda pendente em sua época. Desviei agora de novo do quadro para o registro da referência à vida de Velásquez. É que o repertório do espectador certamente vem, vez por outra, invadir o processo de formação de imagens despertadas. É inevitável a interrupção. Embora os pensamentos da referencialidade consigam, por vezes, essa interrupção, a tela de Velásquez traz a recepção de volta ao artista e à pintura, entrando em compasso de espera com o olhar de prazer intrínseco à composição. Sendo sempre variadas as sensações, é possível que outros significados venham também se alojar no trânsito daqueles cujas mentes elegeram essa figura como uma das mais dignas a ser contemplada: o retoque em busca de maior precisão, o instante anterior à tinta de beleza inaugural, a combinação de tom capaz de retirar o automatismo perceptivo, enfim, o tempo em que o pintor pensa o fazer artístico em busca da mais perfeita forma. Tudo constitui parte fundamental da poiesis e aisthesis de uma bela pintura. Uma pintura enobrecida por si e pela assinatura de Diego Velásquez.

Como é o nome que se liga à ideia de produção, lembro que, em Hegel, o ofício do artista recebera uma síntese das mais apropriadas como ato de poiesis. Disse ele, Hegel, que, pela criação, o artista pode satisfazer a necessidade de retirar, "do mundo externo, a dura estranheza, a fim de que goze, na forma das coisas, apenas uma realidade alheia a si própria" (HEGEL apud JAUSS, 1979, p. 80). Trata-se de um exercício através do qual o indivíduo atinge um saber, um saber de fluida nomeação, acrescentaria, por se configurar distante tanto do conhecimento próprio ao campo conceitual, quanto daquele outro relativo às atividades possibilitadoras de objetos reproduzidos em série. É possível ser que tal sensação de transcendência, em Hegel, falada pela noção de realidade não familiar, defina melhor o estado em que nos percebemos envolvidos, quando nos colocamos diante de Las meninas. 
Obviamente, não se esgotam aí as significações despertadas ${ }^{7}$ pela obra do pintor espanhol na estética a ser vivida por quem se move à revisitação. A produção não dispensa a recepção de múltiplos efeitos imagéticos. No interior da representação da representação ${ }^{8}$, sustentada por um cavalete, a tela do artista personagem que retrata o rei Felipe IV e sua esposa se dispõe de costas para nós, ao passo que, na representação por inteiro de Las meninas, visualizamos outras tantas figuras do quadro. Direcionando o olhar para elas e por intervalos da superfície, descobrimos logo que vários signos se revelam diretamente para recepção. Comparados ao artista personagem, pelo passo de recuo, aprofundamos a imagem do pintor, e concluímos que ele é, simultaneamente, "modelador" e modelo representado. Mostra-se a nós, espectadores, retrato ele mesmo, como se fizesse um convite para que façamos parte da criação, da aisthesis, da katharsis e daí possamos, com ele, "nos libertar dos interesses práticos e das implicações cotidianas para atingir o estágio da liberdade estética em sua capacidade de julgar" (HEGEL apud JAUSS: 1979, p.81). Parece querer que vivenciemos o vir a ser presença e o vir a ser deleite. Como se pressentisse a necessidade de bem receber nossa visita ao ateliê, o pintor se apresenta como um cortesão ricamente vestido. A família real não nos vê? Se puder ver, qual será ao final nosso lugar? Como e onde a recepção se alojará na aceitação do convite? A continuidade a ser dada tais indagações da recepção reflexiva $a^{9}$ conduz o olhar para outro espaço do quadro.

Lá, no fundo da tela, onde o retrato dos reis se faz duplo pelo reflexo do espelho, encontram-se as personagens postadas quase que ao lado de uma cortina, justo no lugar em que nós, observadores, devemos estar para poder atingir o que a tela esconde e revela. Através de uma rede de linhas em perspectivas, como bem nos ensinou Michel Foucault (1966) na bela descrição em páginas de abertura de seu livro As palavras e as $\operatorname{coisas}^{10}$, cruzam-se olhares vários até chegar às primeiras pinceladas da representação dos reis. Dessa

\footnotetext{
${ }^{7}$ A expressão é da corrente estruturalista, embora o texto que desenvolvo em nada se assemelhe a uma análise, tal como é conceituada em “A perversão do trapezista - o romance em Cornélio Penna" (LIMA,1976) para lembrar que autor Luiz Costa Lima , com o conceito de significações despertadas, se aproxima do que Wolfgang Iser veio a denominar efeito: “(...) o papel do sentido é testar, corrigir,outras vezes ampliar o que se apreende pelas significações despertadas no analista da obra. Isso quer dizer que concebemos a tarefa do analista como a distinção entre dois efeitos e um plano - o plano do sentido - a construir” (LIMA: 1976, p. 16).

${ }^{8}$ A expressão "representação da representação" é aqui conceitual. A repetição deve-se ao fato de representação estar se referindo ao objeto quadro de Velásquez e à conceituação, pensada por Foucault, através deste quadro, da representação mesma do sujeito clássico, como centro do conhecimento, condutor da história, aquele que sabe representar, domina a representação, o sujeito, enfim que encerra em si a condução das palavras e das coisas.

${ }^{9}$ Recepção reflexiva é expressão usada por Karlheinz Stierle, teórico da Estética da recepção, para caracterizar a literatura que atrai a percepção para a auto referencialidade da obra, numa espécie de força centrípeta, em oposição às que expulsam o leitor para a referencialidade pragmática.

${ }^{10}$ FOUCAULT, Michel. Las Meninas. In: As palavras e as coisas. Uma arqueologia das ciências humanas. SP: Martins Fontes, 1966, p. 17-33.
} 
vez, pela descrição de um discurso poético-filosófico, a experiência estética resulta de imagens visuais e poéticas, fazendo-se valer como forças de tensão. Se nossa mente, naquele lugar fugidio entre o sensório e o conceitual, for capaz de reter memorativamente os efeitos do texto de Foucault e os do quadro de Velásquez, somos logo arrebatados por dupla sensação de ordem perceptiva. Perpassam pelos sentidos o prazer pela obra de Velásquez e o prazer, também poético, resultante do modo como os signos linguísticos se combinam, em forma e substância, na beleza do ensaio que é o discurso filosófico de Foucault (1966). Percebemonos numa realidade desfamiliarizada, tal qual o pintor e o filósofo, experimentando, cada um a seu modo, a estética na experiência de fazer arte. Deparamo-nos com emoções várias, provocados que somos por palavras e ritmos frasais sonoros que, em tempo certo, se juntam como se fossem notas de solo e acordes musicais construídos em perfeita harmonia. As páginas do ensaio conduzem-nos a admirar uma rede de múltiplos olhares: desde a linha imaginariamente tracejada para ligar o campo de nossa visão ao da representação dos monarcas, passando pela outra que vem de fora, até chegar aos olhos do pintor e, por fim, se dobrar para atingir a tela escondida e todas outras mais, cuidadosamente ordenadas no texto Las Meninas. As linhas de Foucault provocam a formação de outras. Algumas só se formam pela imaginação construtiva da seleção/combinação do texto de Foucault, como a que liga as figuras dos monarcas ao espelho; outras poderiam receber um outro tipo de pontilhado, ainda que só visualmente imaginado, unindo o espaço entre as duas damas de honra e a infanta Margarita. Pela imitação do ensaio de Foucault, permitimo-nos ainda acréscimos, em forma

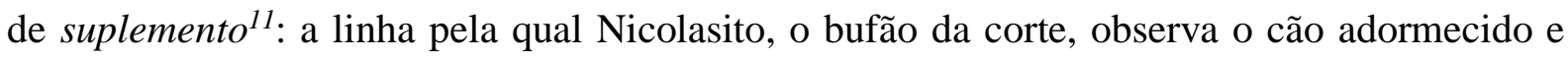
pisa em suas costas e, desse tracejado, advém um significado marcante da cena, quando verificamos que a espontaneidade do ato do fanfarrão contrasta com a formalidade intrínseca ao ritual da nobreza. O convívio de rei, rainha e infanta com outros habitantes no espaço de liberdade da arte de um palácio reveste-se de atitudes solenes e descontraídas, todas a um só tempo, todas vividas num mesmo lugar.

E o homem na escada ao fundo do salão? Quem é ele? É José Nieto. Por ter a importante função de cuidar dos aposentos, o camareiro de maior prestígio da corte, tendo por ali passado, pôde surpreender a intimidade de um dia de ateliê. Tal qual na literatura em que certos signos, apenas inicialmente se revelam como índices para, em seguida, ganharem dimensão estética em função do valor resultante da significação formulada em contraste e

11 Para aprofundamento do conceito, ver A estrutura, o signo e o jogo no discurso das ciências humanas. In: DERRIDA, Jacques. A escritura e a diferença. SP: Perspectiva, 1967, p.227-248. 
semelhança com outros signos linguísticos, esse homem, José Nieto, aparentemente sem importância, aproxima-se, aos poucos, e ganha relevo de significado na comparação com a figura do pintor. Também ele traz a ilusão de um movimento, quando abre a cortina e se responsabiliza pela entrada de luz. O fundo da gestalt não é marginal. É igualmente figura, uma figura que suplementa.

As personagens do quadro, de costas para ele, não percebem sua chegada. O pintor, a futura imperatriz, as damas de honra, a anã, Nicolasito, a freira, o padre, o cão, enfim, todos os que vemos não o veem, não se importam com sua chegada. No entanto, José Nieto pode ser visto pelo rei e pela rainha, as figuras primeiras da hierarquia na realeza. Felipe IV e a esposa podem vê-lo, como o podem também os espectadores, embora rei e rainha fujam de nós de uma visão ampliada, limitados que se encontram ao ato de posar para o artista. De novo, a leitura depara-se aí com o jogo entre revelar e esconder. Pois é justamente essa situação de simples observador que permite que José Nieto assuma uma função fundamental no quadro: sua silhueta fecha o espaço no qual a luz de fora quer aparecer e insinua que o olhar do espectador deve se voltar para o reflexo do rei e da rainha no espelho. Se nós, observadores e monarcas, ocupamos esse mesmo lugar em função das normas da representação clássica, devemos essa honra, em muito, ao modo como, no quadro, aparece o encarregado dos aposentos do palácio. Apoiando o braço na cortina e vindo do lado de fora, para num espaço de penetração de uma das principais fontes de luz nessa obra de Velásquez. É ele também, então, um elemento significativo para que os receptores participem da cena. A timidez de quem parece querer ficar alheio ao convívio de reis e cortesãos é tematizada, na representação, pelo avesso do significado de quem ocupa o lugar recatado. A representação faz de José Nieto a figura que precisa aparecer, que merece ser vista, que deve ser observada. Não por acaso, quando o olhar do espectador vai até José Nieto, percebe, nesse trajeto, que o pintor representou um teto em grandes dimensões, criando, assim, a ilusão do espaço. A ausência dos candelabros, verificada somente pelo contraste da presença de suportes vazios, conduz de volta o olhar para o fundo do salão. Foi dele que Velásquez compôs um dos mais belos efeitos de luz e sombra dentre vários outros de sua pintura, já tão celebrizados pela história da arte.

Muito se poderia falar sobre percepções de ordem estético-recepcionais a partir da tela de Velásquez Las meninas, mas seria impossível não entrar um pouco na filosofia de Foucault pelo tanto que representa de tradição sua leitura de Velásquez. Foi dela que o filósofo se valeu para ilustrar uma das concepções de sujeito que descreve ao longo de As palavras e as 
coisas (1966). Na época clássica, o homem foi compreendido como o mais digno de ser pensado. Não só podia dominar a representação, como ter a capacidade de se representar. Tinha o conhecimento de si e dos outros. Nele repousava o núcleo de todas as coisas de mundo. Abandonando a lembrança nessa forma assertiva, volto para o campo da percepção estética que, dessa vez, se viu concedida pelo privilégio de orientar a escrita. Pensemos na possibilidade inicial de uma leitura diversa da que vimos realizando para, em seguida, contrastá-las com a que vem orientando a leitura.

Em Las meninas, a variabilidade de signos em semelhança, diferença, oposição, em diversidade suscitaria outras articulações imagéticas, semelhantes às que costumamos formular quando interagimos com o discurso literário por uma metodologia estrutural e estruturante de um sentido a ser construído. Por processo semelhante ao da interpretação linguística em que (des)cobrimos o literário pela forma do conteúdo ${ }^{12}$, recortaríamos também semiologicamente, na textura, na cor, na perspectiva, no sombreado, na luminosidade, vários significados para falar do signo visual. Mas o que a tela de Velásquez já estimula em sua mais visível superfície é o suficiente para que apenas ponha em ebulição a beleza, e nos limitemos a sublinhar traços, figuras, cor, sombra, luz. Claro está, me parece, que trato do campo da escritura, da desconstrução da leitura de fundo, meio que dando as costas para o estruturalismo. Mas também contribuiu, neste final, para a tomada de caminho da dobra na leitura foi uma lembrança das reflexões de Santo Agostinho sobre o prazer no uso dos sentidos quando Velásquez aproxima figuras de meninas.

Como sabemos, em suas Confissões (1973), Santo Agostinho trata da diferença entre a ideia de voluptas, o uso dos sentidos para o prazer, e a de curiositas, o uso dos sentidos para a curiosidade. Enquanto a primeira se refere ao belo e harmonioso, a segunda define-se pelo oposto, pelo disforme, pelo que causa horror, como ocorre com a fascinação pelo cadáver mutilado. Olhemos o retrato de Mari-Bárbola, a anã favorita da corte, que se encontra bem atrás do cão adormecido. Seus traços grosseiros, olhar endurecido, traje severo, membros curtos demais embutidos em roupa escura, tudo aí contribui para que se instaure a sensação de feiura da natureza humana de uma moça. Viremos agora o olhar um pouco mais para a esquerda. A contraface do prazer em mesma moeda advém da figura de Margarita. A frescura da pele nos cinco anos da futura imperatriz, o tom do cabelo, a cor clara do vestido

12 A forma do conteúdo pode ser sintetizada pela seguinte equação: ER (ERC), ou seja, há uma relação (primeiro "R") entre o plano da expressão ("E") e o plano do conteúdo ("ERC") que, por sua vez, pressupõe relação, também, entre expressão e conteúdo. HJELMSLEV, Louis. Prolegômenos a uma teoria da linguagem. SP: Perspectiva, 1975. 
carregam os sentidos para a visão harmoniosa das feições, visão do agradável de se ver. Ainda que não vivenciemos o que Agostinho disse ser o prazer voltado para Deus, a inevitável comparação entre as meninas concedeu à arte o poder da aisthesis a partir da diferença. $\mathrm{O}$ feio e o belo ocupam, de perto, o mesmo espaço e, em contraste, ambos podem atrair para a katharsis. Regozijamo-nos tanto com a beleza da infanta quanto com a feiura da anã. A arte provoca percepções estéticas tanto na perfeição da escultura de Da Vinci, quanto no horror do alfinete nos olhos na tragédia de Sófocles.

Difícil fugir, neste momento, de uma citação de Jauss, referindo-se às reflexões de Aristóteles sobre a experiência estética. Isso se deve a um simples, mas profundo apego à origem:

\begin{abstract}
“ (...) a experiência estética não se esgota em um ver cognoscitivo (aisthesis) e em um reconhecimento perceptivo (anamnesis): o espectador pode ser afetado pelo que se representa, identificar-se com as pessoas em ação, dar assim livre curso às paixões despertadas e sentir-se aliviado por sua descarga prazerosa, como se participasse de uma cura (katharsis). Esta descoberta e justificação do prazer catártico, com a qual Aristóteles corrigia o 'mecanismo do efeito direto', sobre o qual Platão apoiara sua condenação da arte, é por certo a herança mais provocante da teoria antiga do poético. Dela se poderia dizer - o que a estética psicanalítica apenas confirmou - que 'nos deu a única resposta até hoje convincente sobre a questão de por que a contemplação do mais trágico acontecimento nos causa o mais profundo prazer." (JAUSS: 1979, p.65, grifo meu).
\end{abstract}

\title{
Referências bibliográficas:
}

AGOSTINHO, Santo. Confissões de Santo Agostinho. São Paulo: Abril cultural, 1973.

COSTA LIMA, Luiz (coordenação e tradução) A literatura e o leitor. Textos de estética da recepção. RJ: Paz e Terra, 1979.

ELLIOT, T. S. “Tradição e Talento individual”. In: Ensaios. Tradução de Ivan Junqueira. São Paulo: Art. Editora, 1989, p. 37-47.

FOUCAULT, Michel. As palavras e as coisas. Uma arqueologia das ciências humanas. SP: Martins Fontes, 1966.

GIESZ, Ludwig. Phãnomonologie des Kitsches . Munchen, 1971.

HJELMSLEV, Louis. Prolegômenos a uma teoria da linguagem. SP: Perspectiva, 1975. 


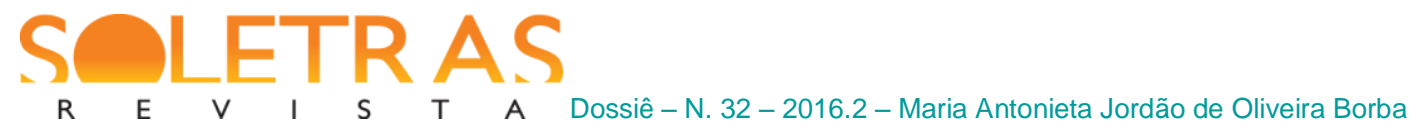

ISER, Wolfgang. The act of reading: a theory of äesthetic response. London: Routledge and Kegan Paul Ltd., 1978.

JAUSS, Hans Robert. “O prazer estético e as experiências fundamentais da Poiesis, Aisthesis e Katharsis". In: COSTA LIMA, Luiz. A literatura e o leitor: textos de estética da recepção, Rio de Janeiro: Paz e Terra, 1979, p.63-82.

LIMA, Luiz Costa. A Perversão do Trapezista - o romance em Cornélio Penna. RJ: Imago Editora, 1976.

POE, Edgar Allan. “A Filosofia da composição” In: Poemas e ensaios. PA: Globo, 1999, p.101-112.

O Corvo e Suas traduções. São Paulo: editora Lacerda, 1998.

SANTOS, Roberto Corrêa. Para a construção transdisciplinar de uma Teoria da arte. Projeto do Programa Prociência. UERJ/FAPERJ, 2016.

\title{
Theory of effect and philosophical discourse's contributions to the contemplation of visual arts
}

\begin{abstract}
A reading of the painting Las meninas, by Diego Velásquez, from different conceptions of Literary Studies, especially the theory of äesthetic response by Wolfgang Iser (1978). Phenomenological perceptions and conceptual configurations, originated at the production and reception of discourse, whether coming from linguistic or semiological syntax. The encounter between artist and reader/spectator. Impressions on The Raven, by Edgar Allan Poe, in the illustration of effect resulting from aesthetic pleasure. By way of these directives, the article is developed in the sense of allowing the writing to reveal data from remembrances by letting themselves go through perceptive occurrences, as if they were occurring at the very moment of their receptive production. In this process of interaction of reader/spectator with work/artist as a phenomenology experiment as in Iser's Act of reading, everything - images, concepts, philosophical discourses, short stories, essays - comes to inhabit this folding, in accordance with Gilles Deleuze, through which the article wants to build itself. It is a differentiated mode of development in the essayistic writing on an object, focused on the objective of contributing to a reflection on the expanded field of art, in which it does not characterize itself through interdisciplinarity exactly, but rather by transdisciplinary ideas and traces of thinking that eventually touch each other in a new critic of art.
\end{abstract}

Key words: Phenomenology. Perception. Effect. Reception. Art theory.

Recebido em: 18 de novembro de 2016.

Aprovado em: 4 de janeiro de 2017. 